\title{
Sistem Pendukung Keputusan Pemilihan Beasiswa Pasca Sarjana Menerapkan Metode Analytic Hierarchy Process(AHP) dan Weight Aggregated Sum Product Assessment(WASPAS) (StudiKasus: STMIK Budi Darma)
}

\author{
Garuda Ginting1, Mesran'2 ${ }^{2}$ KurniaUlfa ${ }^{3}$ \\ STMIK Budi Darma, Medan, Indonesia \\ Email: mesran.skom.mkom@gmail.com
}

\begin{abstract}
Continuing education to post-graduate level, even doctoral is the dream of all educators, in this case, lecturers. However, the limited cost is one of the obstacles encountered by a lecturer. The existence of scholarships given by institutions to lecturers to continue their education is a dream for a lecturer. But in awarding the scholarship, use the criteria set, so that the awarding of post-graduate scholarships to selected lecturers is correct and free of errors. For this reason, the author intends to conduct research on the selection of post-graduate scholarships by applying the AHP and WASPAS methods. AHP is used to produce weights on each criterion according to the priority of the criteria for awarding a post-graduate scholarship. While the WASPAS method is used to rank the alternatives. It is expected that the results of the study will provide effective results for the institution towards recipients of post-graduate scholarships.
\end{abstract}

Keywords: DSS, Scholarship Selection, AHP, WASPAS

Abstrak- Melanjutkan pendidikan kejenjang pascasarja, bahkan doktoral merupakan impian semua pendidik, dalam hal ini dosen. Namun keterbatasan biaya merupakan salah satu hambatan yang di temui oleh seorang dosen. Adanya beasiswa yang diberikan oleh institusi kepada dosen untuk melanjutkan sekolah merupakan impian bagi seorang dosen. Namun dalam pemberian beasiswa tersebut, menggunakan kriteria-kriteria yang di tetapkan, agar pemberian beasiswa pascasarjana kepada dosen yang terpilih sudah tepat dan bebas dari kesalahan. Untuk itu pada panelitian ini penulis berkeinginan untuk melakukan penelitian pemilihan beasiswa pascasarja dengan menerapkan metode AHP dan WASPAS. AHP digunakan untuk menghasilkan bobot pada setiap kriteria sesuai dengan prioritas dari kriteria pemberian beasiswa pascasarjana yang ditetapkan. Sedangkan metode WASPAS di gunakan untuk melakukan perangkingan terhadap alternatif yang dimiliki. Diharapkan hasil penelitian memberikan hasil yang efektif bagi institusi terhadap penerima beasiswa pascasarjana.

Kata Kunci: DSS, PemilihanBeasiswa, AHP, WASPAS

\section{PENDAHULUAN}

Melanjutkan sekolah, kejenjang pendidikan yang lebih tinggi, merupakan salah satu kewajiban dosen pada suatu institusi pendidikan formal. Ini juga merupakan salah satu aspek di dalam tridarma perguruan tinggi, yaitu Pendidikan dan 
Pengajaran. Sehingga dosen pada suatu institusi pendidikan, bukan hanya menekankan pada pengajarannya saja, namun juga harus mempertimbangkan untuk melanjutkan kependidikan yang lebih tinggi, misalnya sekolah pascasarjana. Namun terkadang harapan yang diinginkan oleh dosen, tidak semudah itu terpenuhi. Tidak adanya dana pendidikan merupakan faktor penghambat bagi dosen untuk melanjutkan pendidikannya. Harapan yang dapat dicapai, tentunya yaitu mendapatkan beasiswa pendidikan. Beasiswa pendidikan bisa berikan oleh yayasan, maupun beasiswa yang di programkan oleh pemerintah. Beasiswa pendidikan dari yayasan merupakan satu-satu kewajiban yang harus diberikan oleh yayasan kepada dosen tetap yang dimilikinya. Dalam pemberian beasiswa tersebut, agar lebih tepat penerimanya, tentu harus mempertimbangkan kriteria-kriteria yang ditetapkan. Ini bertujuan agar proses pemberian beasiswa kepada dosen tetap pada perguruan tinggi menjadi lebih efektif dan tidak salah sasaran. Walaupun semua semua dosen berhak untuk mendapatkan beasiswa yayasan ini, namun terkendalanya dana yang dimiliki oleh yayasan, menjadi faktor utama, bahwa pemberian beasiswa itu harus lebih selektif. Beberapa kriteria yang dapat dijadikan syarat dalam memperoleh beasiswa yayasan, diantaranya masa kerja, kompetensi dosen, kerjasama, jabatan menjadi dasar dalam pemberian beasiswa tersebut. Untuk menjadi penerima beasiswa tersebut lebih efektif, maka dibutuhkan sistem pendukung keputusan(SPK). Penerapan SPK dengan menggunakan metode-metode dalam pemrosesannya, diantaranya metode Promethee, Exprom II, Preference Selection Index(PSI), VIKOR, AHP, ARAS, OCRA[1]-[4]. SPK merupakan sistem yang diperuntukkan bagi manajemen untuk menyelesaikan permasalahan yang dihadapi[5]-[7].

Berdasarkan pembahasan diatas, pada penelitian ini akan dibahas pemilihan penerima beasiswa sekolah pascasarjana bagi dosen tetap di STMIK Budi Darma dengan mengkombinasikan metode Analytic Hierarchy Process (AHP) dan Weight Aggregated Sum Product Assement (WASPAS), sehingga hasil yang didapat, mampu menyelesaikan permasalahan yang dihadapi oleh pihak yayasan STMIK Budi Darma.

\section{METODOLOGI PENELITIAN}

\subsection{Kerangka Penelitian}

Dalam penelitian ini, terdapat beberapa tahapan, yaitu:
a) TahapanPengumpulan data
b) Tahapan Studi Literatur
c) Tahapan Analisa Masalah
d) Tahapan Pengujian Metode
e) Tahapan Implementasi
f) Tahapan Dokumentasi

\subsection{Metode Analytic Hierarchy Process (AHP)}

Metode AHP merupakanmetode yang digunakan untuk penentuan bobot berdasarkan prioritas dari suatu kriteria [8]-[10]. Penentuan nilai rating terhadap 
prioritas kriteria sesuai dengan tabel saaty. Langkah-langkah metode AHP[11][9], terdiri dari beberapa tahapan, sebagai berikut:

a) Membuat matrik perbandingan berpasangan.

Pada perbandingan matrik berpasangan berdasarkan tabel Saaty dalam penilaian setiap prioritas kriteria.

Tabel 1. Skala Penilaian Perbandingan Pasangan.

\begin{tabular}{|l|l|}
\hline Intesitas Kepentingan & Keterangan \\
\hline 1 & Kedua elemen sama pentingnya \\
\hline 3 & Elemen yang satu sedikit lebih penting dari pada elemen yang lainya \\
\hline 5 & Elemen yang satu lebih penting dari pada yang lainya \\
\hline 7 & Satu elemen jelas lebih mutlak penting dari pada elemen lainya \\
\hline 9 & Satu elemen mutlak penting dari pada elemenlainya \\
\hline $2,4,6,8$ & Nilai-nilai antara dua nilai pertimbangan-pertimbangan yang berdekatan \\
\hline
\end{tabular}

Selanjutnya dari tabel tersebut di masukkan nilainya menjadi suatu matrik berpasangan seperti pada persamaan 1 .

$$
\mathrm{W}=\left[\mathrm{w}_{1} / \mathrm{w}_{\mathrm{j}}\right]=\left[\begin{array}{cccc}
w_{1} / w_{1} & w_{1} / w_{2} & \ldots & w_{i} / w_{n} \\
w_{2} / w_{1} & w_{2} / w_{2} & \ldots & w_{2} / w_{n} \\
\ldots & \ldots & \ldots & \ldots \\
w_{n} / w_{1} & w_{n} / w_{1} & \ldots & w_{n} / w_{n}
\end{array}\right]
$$

b) Setelah ini, pembuat keputusan membandingkan pasangan alternatif untuk semua pasangan yang mungkin, dan matriks perbandingan A diperoleh, di mana elemen $\mathrm{a}_{\mathrm{ij}}$ menunjukkan bobot preferensi $A_{i}$ yang diperoleh dengan membandingkan dengan $\mathrm{A}_{\mathrm{j}}$

$$
\mathrm{A}=\left[\mathrm{a}_{\mathrm{ij}}\right]=\left[\begin{array}{cccc}
1 & a_{12} & \ldots & a_{1 n} \\
1 / a_{1} & 1 & \ldots & a_{2 n} \\
\ldots & \ldots & \ldots & \ldots \\
1 / a_{1 n} & 1 / a_{2 n} & \ldots & 1
\end{array}\right]
$$

Elemen ai memperkirakan rasio $\mathrm{w}_{\mathrm{i}} / \mathrm{w}_{\mathrm{j}}$, dimana $\mathrm{w}$ adalah vektor bobot alternatif saat ini (yang merupakan tujuan). Matriks memiliki sifat timbal balik, yang $\mathrm{a}_{\mathrm{ji}}=$ $1 / a_{i j}$.

Setelah semua matriks perbandingan pasangan terbentuk, vektor bobot $\mathrm{w}=\left[\mathrm{w}_{1}\right.$, $\left.\mathrm{w}_{2}, \ldots, \mathrm{w}_{\mathrm{n}}\right]$ dihitung berdasarkan prosedur vector eigen Satty dalam dua langkah. Matriks perbandingan berpasangan, $A=\left[a_{i j}\right]$ nxn, dinormalisasi, dan kemudian bobotnya dihitung.

Normalisasi:

$\boldsymbol{a}_{i j}^{*}=\mathrm{a}_{\mathrm{ij}} / \sum_{i=j}^{n} \boldsymbol{a}_{i j} \quad \mathrm{j}=1,2, \ldots, \mathrm{n}$

Perhitungan bobot

$\mathrm{W}_{\mathrm{i}}=\sum_{i=1}^{n} \boldsymbol{a}_{\boldsymbol{i j}}^{*} / \boldsymbol{n} \quad \mathrm{j}=1,2, \ldots, \mathrm{n}$ 
b) Untuk perbandingan yang valid, kita perlu memeriksa konsistensi dari matrik berpasangan (CI).

$\mathrm{CI}=(\lambda$ maks $\mathrm{n}) /(\mathrm{n}-1)$

Keterangan :

n : banyaknyaelemen

$\lambda \max \quad$ : parameter validasi pada AHP

c) LangkahselanjutnyamenghitungRasioKonsistensi.

$\mathrm{CR}=\mathrm{CI} / \mathrm{IR}$

Keterangan:

CR : Consistency Ratio

CI : Consistency Index

IR : Indeks Random Consistency

Jika $\mathrm{CR}<0.1$, maka perbandingannya dapat diterima. Jika $\mathrm{CR} \geq 0,1$, nilai-nilai rasio menunjukkan penilaian yang tidak konsisten. Dalam hal ini, nilai-nilai asli dalam matriks perbandingan pasangan A harus dipertimbangkan kembali. Daftar Indeks Random Konsistensi (IR) bisa dilihat dalam tabel 2.

Tabel 2. Daftar Indeks Random Konsistensi

\begin{tabular}{|l|l|}
\hline Ukuran Matriks & Nilai IR \\
\hline 1,2 & 0,00 \\
\hline 3 & 0.58 \\
\hline 4 & 0.90 \\
\hline 5 & 1.12 \\
\hline 6 & 1.24 \\
\hline 7 & 1.32 \\
\hline 8 & 1.41 \\
\hline 9 & 1.45 \\
\hline 10 & 1.49 \\
\hline 11 & 1.51 \\
\hline 12 & 1.48 \\
\hline 13 & 1.56 \\
\hline 14 & 1.57 \\
\hline 15 & 1.59 \\
\hline
\end{tabular}

\subsection{MetodeWeight Aggregated Sum Product Assement(WASPAS)}

WASPAS merupakan metode yang dapat mengurangi kesalahan-kesalahan atau mengoptimalkan dalam penaksiran untuk pemilihan nilai tertinggi dan terendah. Waspas merupakan kombinasi dari metode SAW dan WP [12], [13]. Proses perhitungan metode WASPAS [14]-[16]:

a) Tetapkan sebuah matrix keputusan 


$$
X_{I J}=\left[\begin{array}{lll}
x_{11} & \ldots & x_{1 n} \\
x_{21} & \ldots & x_{2 n} \\
x_{31} & \cdots & x_{3 n}
\end{array}\right]
$$

b) Proses normalisasi terhadap MatrikX $\mathrm{X}_{\mathrm{ij}}$ Kriteria Benefit

$$
\bar{x}=\frac{\mathrm{Xij}}{\operatorname{Max} \mathrm{Xij}}
$$

KriteriaCost

$$
\bar{x}=\frac{\operatorname{Min} \mathrm{Xij}}{\mathrm{Xij}}
$$

c) Menghitung nilai Preferensi $Q_{i}$

$$
\mathrm{Qi}=0.5 \sum_{j=1}^{n} X i j W j+0.5 \bigsqcup_{j=1}^{n} X i j^{\mathrm{Wj}}
$$

Alternatif yang terbaik merupakan alternatif yang memiliki nilai Qi tertinggi.

\section{HASIL DAN PEMBAHASAN}

Pada proses penentuan penerimaan beasiswa pascasarjana, dibutuhkan sistem pendukung keputusan yang dapat membantu dalam membuat dalam mengefektifkan suatu keputusan dalam memilih penerima beasiswa pascasarjana. Pada penelitian ini, akan mengkombinasikan penerapan metode AHP dan WASPAS. Pada langkah awal akan ditentukan prioritas kriteria sehingga dapat menghasilkan bobot yang akan dibutuhkan dalam proses perhitungan WASPAS. Berikut kriteria yang digunakan dalam penentuan penerima beasiswa pascasarjana.

Tabel 3. Kriteria Penentuan Beasiswa

\begin{tabular}{|l|l|l|}
\hline Kriteria & Keterangan & Jenis \\
\hline$C_{1}$ & Masa Kerja & Benefit \\
\hline$C_{2}$ & Golongan & Benefit \\
\hline$C_{3}$ & PejabatStruktural & Benefit \\
\hline$C_{4}$ & Kinerja & Benefit \\
\hline$C_{5}$ & Umur & Cost \\
\hline
\end{tabular}

Dari tabel 3, akan dilakukan perhitungan menerapkan metode AHP untuk menentukan bobot, berdasarkan langkah berikut:

Lakukan analisis berpasangan antar lima kriteria yang sudah ditentukan.

a. FaktorMasa Kerja yaitu menunjukan masa kerja dari dosen dalam bekerja

b. Faktor Golongan yaitu, tingkatan golongan dosen dalam jabatan dosen.

c. Faktor Pejabat Struktural yaitu dosen yang menjabat pada STMIK Budi Darma.

d. Faktor Kinerja yaitu keterangan dari kerjasama dan tanggung jawab sebagai dosen.

e. Faktor Umur yaitu usia dari dosen. 
Prosiding Seminar Nasional Riset Information

ISSN: 2686-0260

Science (SENARIS)

September 2019

$\mathrm{Hal}: 835-845$

Kebijakan bagi pengambil keputusan dengan menilai tingkat kepentingan antara satu elemen dengan elemen yang lainnya. Dari kriteria tersebut dapat dilihat matrik perbandingan:

Tabel 4. Matrik Perbandingan untuk Kriteria

\begin{tabular}{|l|l|l|l|l|l|}
\hline & C1 & C2 & C3 & C4 & C5 \\
\hline C1 & 1 & 3 & 3 & 7 & 7 \\
\hline C2 & $1 / 3$ & 1 & 3 & 2 & 4 \\
\hline C3 & $1 / 3$ & $1 / 3$ & 1 & 3 & 3 \\
\hline C4 & $1 / 7$ & $1 / 2$ & $1 / 3$ & 1 & 2 \\
\hline C5 & $1 / 7$ & $1 / 4$ & $1 / 3$ & $1 / 2$ & 1 \\
\hline
\end{tabular}

Tabel 5. Matrik Perbandingan untuk Kriteria yang disederhanakan

\begin{tabular}{|l|l|l|l|l|l|}
\hline & C1 & C2 & C3 & C4 & C5 \\
\hline C1 & 1 & 3 & 3 & 7 & 7 \\
\hline C2 & 0.333 & 1 & 3 & 2 & 4 \\
\hline C3 & 0.333 & 0.333 & 1 & 3 & 3 \\
\hline C4 & 0.143 & 0.500 & 0.333 & 1 & 2 \\
\hline C5 & 0.143 & 0.250 & 0.333 & 0.5 & 1 \\
\hline$\sum$ Kolom & $\mathbf{1 . 9 5 2}$ & $\mathbf{5 . 0 8 3}$ & $\mathbf{7 . 6 6 7}$ & $\mathbf{1 3 . 5 0 0}$ & $\mathbf{1 7 . 0 0 0}$ \\
\hline
\end{tabular}

Dengan unsur-unsur pada setiap kolom dibagi dengan jumlah total pada kolom yang bersangkutan, akan diperoleh bobot relatif yang dinormalkan. Berikut merupakan perhitungan bobot yang dinormalkan:

Untuk C1:

$1,000: 1,965=0,512$

$0,333: 1,965=0,171$

$0,333: 1,965=0,171$

$0,143: 1,965=0,073$

$0,143: 1,965=0,073$

Langkah yang sama dilakukan untuk C2 hingga C5.Berikut hasil perhitungannya:

Tabel 6. Matrik Perbandingan untuk Kriteria yang dinormalkan

\begin{tabular}{|c|c|c|c|c|c|c|c|}
\hline & C1 & $\mathrm{C} 2$ & C3 & C4 & C5 & $\Sigma$ Baris & Eigen Vektor \\
\hline C1 & 0.512 & 0.590 & 0.391 & 0.519 & 0.412 & 2.424 & 0.485 \\
\hline C2 & 0.171 & 0.197 & 0.391 & 0.148 & 0.235 & 1.142 & 0.228 \\
\hline C3 & 0.171 & 0.066 & 0.130 & 0.222 & 0.176 & 0.765 & 0.153 \\
\hline C4 & 0.073 & 0.098 & 0.043 & 0.074 & 0.118 & 0.407 & 0.081 \\
\hline C5 & 0.073 & 0.049 & 0.043 & 0.037 & 0.059 & 0.262 & 0.052 \\
\hline
\end{tabular}

Langkah berikut untuk menghitung nilai eigen vector, dapat dilihat pada perhitungan berikut.

Eigen vector Masa Kerja $=\Sigma$ Baris $/$ kolom

$=2,424 / 5$

$$
=0,485
$$

Pemilihan Beasiswa Pasca Sarjana dengan Metode AHP dan WASPAS(Garuda Ginting) | 840 
Untuk nilai C2 hingga C5, dilakukan langkah yang sama pada langkah diatas. Langkah selanjutnya untuk menghitung nilai maksimum dan rasio konsistensi, dimana $\sum$ kolom dikali dengan bobot, berikut perhitungannya:

$$
\begin{aligned}
\mathrm{W}_{\mathrm{i}} & =(1,952 * 0,485)+\left(5,083^{*} 0,228\right)+(7,667 * 0,153)+(13,50 * 0,081)+(17,0 * 0,052) \\
& =0,946+1,161+1,174+1,098+0,890 \\
& =5,269
\end{aligned}
$$

$\mathrm{Ci}=\frac{5,269-5}{5-1}=0,067$

Karena $\mathrm{n}=5$ makaIR $=1,12$, nilailRdiambil pada tabel2, maka:

$\mathrm{CR}=\frac{C I}{R_{z}^{\epsilon_{z}}}=\frac{0,067}{1,12}=0,060$

Hasil CR bernilai 0,060, yang bernilai lebih kecil dari 0,1 sehingga nilai CR dapat disimpulkan konsisten.

Tabel 7. Nilai Bobot Kriteria

\begin{tabular}{|l|l|l|}
\hline Kriteria & Bobot & Jenis \\
\hline C1 & 0.485 & Benefit \\
\hline C2 & 0.228 & Benefit \\
\hline C3 & 0.153 & Benefit \\
\hline C4 & 0.081 & Benefit \\
\hline C5 & 0.052 & Cost \\
\hline
\end{tabular}

Selanjutnya dilakukan perangkingan terhadap calon penerima beasiswa pascasarjana dengan menerapkan metode WASPAS. Dalam perangkingannya, harus dipersiapkan alternatif karyawan serta bobot dari setiap alternatif, yang dapat dilihat pada tabel 8.

Tabel 8. Alternatif Karyawan

\begin{tabular}{|l|l|l|l|l|l|}
\hline Nama & $\mathbf{C}_{\mathbf{1}}$ & $\mathbf{C}_{\mathbf{2}}$ & $\mathbf{C}_{\mathbf{3}}$ & $\mathbf{C}_{\mathbf{4}}$ & $\mathbf{C}_{\mathbf{5}}$ \\
\hline Nelly $\left(\mathrm{A}_{1}\right)$ & 10 & IIID & Ya & Sangat Baik & 35 \\
\hline Mesran( $\left(\mathrm{A}_{2}\right)$ & 14,7 & IIID & Ya & Sangat Baik & 41 \\
\hline Garuda( $\left(\mathrm{A}_{3}\right)$ & 14 & IIID & Tidak & Baik & 52 \\
\hline Sinar $\left(\mathrm{A}_{4}\right)$ & 13,4 & IIID & Tidak & Baik & 52 \\
\hline Hery $\left(\mathrm{A}_{5}\right)$ & 14 & IIID & Tidak & Baik & 44 \\
\hline Pristiwanto( $\left.\mathrm{A}_{6}\right)$ & 9 & IIIC & Ya & Baik & 37 \\
\hline Saidi $\left(\mathrm{A}_{7}\right)$ & 6 & IIIB & Ya & Sangat Baik & 29 \\
\hline Rivalri $\left(\mathrm{A}_{8}\right)$ & 7,4 & IIIC & Ya & Baik & 30 \\
\hline Guidio $\left(\mathrm{A}_{9}\right)$ & 10 & IIIC & Ya & Sangat Baik & 32 \\
\hline Imam $\left(\mathrm{A}_{10}\right)$ & 5 & IIIB & Ya & Sangat Baik & 27 \\
\hline Fince $\left(\mathrm{A}_{11}\right)$ & 5 & IIIB & Ya & Sangat Baik & 30 \\
\hline Syahrizal $\left(\mathrm{A}_{12}\right)$ & 11 & IIIC & Ya & Sangat Baik & 36 \\
\hline Surya $\left(\mathrm{A}_{13}\right)$ & 8 & IIIC & Tidak & Sangat Baik & 29 \\
\hline
\end{tabular}


Pada tabel alternatif diatas terdapat data data yang masih bersifat linguistik, sehingga harus dilakukan pembobotan sederhana, seperti yang dilakukan pada tabel dibawah ini.

Tabel 9. Kriteria Golongan Kepangkatan

\begin{tabular}{|l|l|}
\hline Keterangan & Nilai \\
\hline IVA & 6 \\
\hline IIID & 5 \\
\hline IIIC & 4 \\
\hline IIIB & 3 \\
\hline IIIA & 2 \\
\hline- & 1 \\
\hline
\end{tabular}

Tabel 10. Kriteria Pejabat Struktural

\begin{tabular}{|l|l|}
\hline Keterangan & Nilai \\
\hline Ya & 2 \\
\hline Tidak & 1 \\
\hline
\end{tabular}

Tabel 11. Kriteria Kinerja

\begin{tabular}{|l|l|}
\hline Keterangan & Nilai \\
\hline SangatBaik & 4 \\
\hline Baik & 3 \\
\hline Cukup & 2 \\
\hline Kurang & 1 \\
\hline
\end{tabular}

Dari hasil pembobotan maka diperoleh data rating kecocokan pada tabel 12.

Tabel 12. Rating Kecocokan

\begin{tabular}{|l|l|l|l|l|l|}
\hline Nama & $\mathbf{C}_{\mathbf{1}}$ & $\mathbf{C}_{\mathbf{2}}$ & $\mathbf{C}_{\mathbf{3}}$ & $\mathbf{C}_{\mathbf{4}}$ & $\mathbf{C}_{\mathbf{5}}$ \\
\hline Nelly $\left(\mathrm{A}_{1}\right)$ & 10 & 5 & 2 & 4 & 35 \\
\hline Mesran $\left(\mathrm{A}_{2}\right)$ & 14,7 & 5 & 2 & 4 & 41 \\
\hline Garuda $\left(\mathrm{A}_{3}\right)$ & 14 & 5 & 1 & 3 & 52 \\
\hline Sinar( $\left(\mathrm{A}_{4}\right)$ & 13,4 & 5 & 1 & 3 & 52 \\
\hline Hery $\left(\mathrm{A}_{5}\right)$ & 14 & 5 & 1 & 3 & 44 \\
\hline Pristiwanto($\left(\mathrm{A}_{6}\right)$ & 9 & 4 & 2 & 3 & 37 \\
\hline Saidi $\left(\mathrm{A}_{7}\right)$ & 6 & 3 & 2 & 4 & 29 \\
\hline Rivalri $\left(\mathrm{A}_{8}\right)$ & 7,4 & 4 & 2 & 3 & 30 \\
\hline Guidio $\left(\mathrm{A}_{9}\right)$ & 10 & 4 & 2 & 4 & 32 \\
\hline Imam $\left(\mathrm{A}_{10}\right)$ & 5 & 3 & 2 & 4 & 27 \\
\hline Fince $\left(\mathrm{A}_{11}\right)$ & 5 & 3 & 2 & 4 & 30 \\
\hline Syahrizal $\left(\mathrm{A}_{12}\right)$ & 11 & 4 & 2 & 4 & 36 \\
\hline Surya $\left(\mathrm{A}_{13}\right)$ & 8 & 4 & 1 & 4 & 29 \\
\hline
\end{tabular}

Pada penentuan perangkingan menerapkan metode WASPAS dapat dilakukan dengan menerapkan langkah berikut. Langkah awal yang harus dipersiapkan yaitu matrik keputusan, seperti terlihat berikut ini. 
Prosiding Seminar Nasional Riset Information

ISSN: 2686-0260

Science (SENARIS)

\begin{tabular}{|l|l|l|l|l|l|}
\hline & $\mathbf{C}_{\mathbf{1}}$ & $\mathbf{C}_{\mathbf{2}}$ & $\mathbf{C}_{\boldsymbol{3}}$ & $\mathbf{C}_{\mathbf{4}}$ & $\mathbf{C}_{\mathbf{5}}$ \\
\hline & 10 & 5 & 2 & 4 & 35 \\
\hline & 14,7 & 5 & 2 & 4 & 41 \\
\hline & 14 & 5 & 1 & 3 & 52 \\
\hline & 13,4 & 5 & 1 & 3 & 52 \\
\hline & 14 & 5 & 1 & 3 & 44 \\
\hline & 9 & 4 & 2 & 3 & 37 \\
\hline $\mathbf{X}_{\mathrm{ij}}=$ & 6 & 3 & 2 & 4 & 29 \\
\hline & 7,4 & 4 & 2 & 3 & 30 \\
\hline & 10 & 4 & 2 & 4 & 32 \\
\hline & 5 & 3 & 2 & 4 & 27 \\
\hline & 5 & 3 & 2 & 4 & 30 \\
\hline & 11 & 4 & 2 & 4 & 36 \\
\hline & 8 & 4 & 1 & 4 & 29 \\
\hline
\end{tabular}

Setelah mendefinisikan matrik keputusan, selanjutnya menghitung matrik ternormalisasi dengan menggunakan persamaan 8 dan 9.

Untuk kriteria Kerjasama yaitu :

$\mathrm{R}_{1,1}=10 / 14,7=0,6803$

$\mathrm{R}_{2,1}=14,7 / 14,7=1$

$\mathrm{R}_{3,1}=14 / 14,7=0,9524$

$\mathrm{R}_{4,1}=13,4 / 14,7=0,9116$

$\mathrm{R}_{5,1}=14 / 14,7=0,9524$

$\mathrm{R}_{6,1}=9 / 14,7=0,6122$

$\mathrm{R}_{7,1}=6 / 14,7=0,4082$

$\mathrm{R}_{8,1}=7,4 / 14,7=0,5034$

$\mathrm{R}_{9,1}=10 / 14,7=0,6803$

$\mathrm{R}_{10,1}=5 / 14,7=0,3401$

$\mathrm{R}_{11,1}=5 / 14,7=0,3401$

$\mathrm{R}_{12,1}=11 / 14,7=0,7483$

$\mathrm{R}_{13,1}=8 / 14,7=0,5442$

Untuk kriteria C2 hingga C5 dapat dilakukan dengan cara diatas. Hasil dari matrik ternormalisasi, yaitu:

\begin{tabular}{|l|l|l|l|l|l|}
\hline & 0.680 & 1.000 & 1.000 & 1.000 & 0.771 \\
\hline & 1.000 & 1.000 & 1.000 & 1.000 & 0.659 \\
\hline & 0.952 & 1.000 & 0.500 & 0.750 & 0.519 \\
\hline & 0.912 & 1.000 & 0.500 & 0.750 & 0.519 \\
\hline & 0.952 & 1.000 & 0.500 & 0.750 & 0.614 \\
\hline & 0.612 & 0.800 & 1.000 & 0.750 & 0.730 \\
\hline & 0.408 & 0.600 & 1.000 & 1.000 & 0.931 \\
\hline$\overline{\boldsymbol{x}}_{\mathbf{i j}}=$ & 0.503 & 0.800 & 1.000 & 0.750 & 0.900 \\
\hline & 0.680 & 0.800 & 1.000 & 1.000 & 0.844 \\
\hline
\end{tabular}

Pemilihan Beasiswa Pasca Sarjana dengan Metode AHP dan WASPAS(Garuda Ginting) | 843 


\begin{tabular}{|l|l|l|l|l|l|}
\hline & 0.340 & 0.600 & 1.000 & 1.000 & 1.000 \\
\hline & 0.340 & 0.600 & 1.000 & 1.000 & 0.900 \\
\hline & 0.748 & 0.800 & 1.000 & 1.000 & 0.750 \\
\hline & 0.544 & 0.800 & 0.500 & 1.000 & 0.931 \\
\hline & 0.680 & 1.000 & 1.000 & 1.000 & 0.771 \\
\hline
\end{tabular}

Selanjutnya menghitung nilai Qi, menggunakan persamaan 10 .

$$
\begin{aligned}
& \mathrm{Q}_{1}=0.5 \sum(0,485 * 0,3299)+(0,225 * 0,2250)+(0,153 * 0,1530)+(0,081 * 0,0810)+ \\
& (0,052 * 0,0401)+0.5 \prod\left(0,32990,485 * 0,2250^{0,225} * 0,1530^{0,153} * 0,0810^{0.081} *\right. \\
& 0,0401^{0.052} \text { ) } \\
& =(0,5 * 0,829)+(0,5 * 0,818)=0,824
\end{aligned}
$$

Perhitungan diatas dilakukan hingga $\mathrm{Q}_{13}$, sehingga menghasilkan nilai yang terlihat pada tabel 13.

Tabel 13. Nilai $Q_{i}$

\begin{tabular}{|l|l|l|}
\hline Nama & Qi & Prioritas \\
\hline Mesran $\left(\mathrm{A}_{2}\right)$ & 0.978 & 1 \\
\hline Hery $\left(\mathrm{A}_{5}\right)$ & 0.846 & 2 \\
\hline Garuda $\left(\mathrm{A}_{3}\right)$ & 0.84 & 3 \\
\hline Nelly $\left(\mathrm{A}_{1}\right)$ & 0.824 & 4 \\
\hline Sinar $\left(\mathrm{A}_{4}\right)$ & 0.822 & 5 \\
\hline Syahrizal $\left(\mathrm{A}_{12}\right)$ & 0.815 & 6 \\
\hline Guidio $\left(\mathrm{A}_{9}\right)$ & 0.785 & 7 \\
\hline Pristiwanto $\left(\mathrm{A}_{6}\right)$ & 0.725 & 8 \\
\hline Rivalri $\left(\mathrm{A}_{8}\right)$ & 0.674 & 9 \\
\hline Surya $\left(\mathrm{A}_{13}\right)$ & 0.642 & 10 \\
\hline Saidi $\left(\mathrm{A}_{7}\right)$ & 0.595 & 11 \\
\hline Imam $\left(\mathrm{A}_{10}\right)$ & 0.557 & 12 \\
\hline Fince $\left(\mathrm{A}_{11}\right)$ & 0.553 & 13 \\
\hline
\end{tabular}

Dari hasil perhitungan dengan menerapkan metode AHP dan WASPAS, dapat dilihat bahwa $\mathrm{A}_{1}$ memiliki nilai prioritas terbaik untuk diberikan beasiswa pascasarjana.

\section{KESIMPULAN}

Dari penelitian yang dilakukan dapat disimpulkan, penggunaan metode AHP dan WASPAS, dalam menentukan penerima beasiswa sekolah pascasarjana pada STMIK Budi Darma, mampu memberikan hasil yang lebih baik. Hasil dari sistem pendukung keputusan dapat menjadi usulan bagi yayasan dalam memberikan bantuan beasiswa tersebut bagi dosen di STMIK Budi Darma.

\section{DAFTAR PUSTAKA}

[1] A. V. Manikrao and C. Shankar, "Facility Location Selection using PROMETHEE II Method," Int. Conf. Ind. Eng. Oper. Manag. Dhaka, pp. 59-64, 2010.

[2] Esra; and AyG̣egül, "AIR CONDITIONER SELECTION PROBLEM WITH COPRAS AND ARAS 
METHODS, Manas J. Soc. Stud., vol. 5, no. 2, 2016

[3] M. A. Hasma, B. Nadeak, N. Sitompul, and M. Mesran, "Sistem Pendukung Keputusan Penerimaan Instruktur Fitness Menerapkan Metode Additive Ratio Assessment (Aras) (Studi Kasus: Vizta Gym Medan)," KOMIK (Konferensi Nas. Teknol. Inf. dan Komputer), vol. 2, no. 1, pp. 121-129, 2018.

[4] M. Mesran, S. D. Nasution, S. Syahputra, A. Karim, and E. Purba, "Implementation of the Extended Promethee II in Upgrade Level of Mechanic," Int. J. Sci. Res. Sci. Technol., vol. 4, no. 2, pp. 125130, 2018.

[5] D. Nofriansyah and S. Defit, Multi Criteria Decision Making (MCDM) pada Sistem Pendukung Keputusan. 2018.

[6] G.-H. Tzeng and J.-J. Huang, Multiple Attribute Decision Making Method And Applications. CRC Press, 2011.

[7] S. Kusumadewi, S. Hartati, A. Harjoko, and Retantyo Wardoyo, "Fuzzy Multi Attribute Decision Making (FUZZY MADM)," Ed. Pertama Cetakan Pertama. Graha Ilmu. Yogyakarta., 2006.

[8] N. Kundakcl, "An Integrated Multi-Criteria Decision Making Approach for Tablet Computer Selection," Eur. J. Multidiscip. Stud., vol. 5, no. 1, p. 36, 2017.

[9] D. Bogdanovic, D. Nikolic, and I. Ivana, "Mining method selection by integrated AHP and PROMETHEE method," An. Acad. Bras. Cienc., vol. 84, no. 1, pp. 219-233, 2012.

[10] H. Nurdiyanto and Heryanita Meilia, "SISTEM PENDUKUNG KEPUTUSAN PENENTUAN PRIORITAS PENGEMBANGAN INDUSTRI KECIL DAN MENENGAH DI LAMPUNG TENGAH MENGGUNAKAN ANALITICAL HIERARCHY PROCESS (AHP)," in Seminar Nasional Teknologi Informasi dan Multimedia 2016, 2016, no. February, pp. 1-7.

[11] K. Safitri, F. T. Waruwu, and M. Mesran, "SISTEM PENDUKUNG KEPUTUSAN PEMILIHAN KARYAWAN BERPRESTASI DENGAN MENGGUNAKAN METODE ANALYTICAL HIEARARCHY PROCESS (Studi Kasus : PT.Capella Dinamik Nusantara Takengon)," MEDIA Inform. BUDIDARMA, vol. 1, no. 1, Feb. 2017.

[12] S. C. and E. K. Zavadskas, "Applications of WASPAS Method in Manufacturing Decision Making," Informatica, vol. 25, pp. 1-20, 2014.

[13] S. Chakraborty and E. K. Zavadskas, "Applications of WASPAS Method in Manufacturing Decision Making," Informatica, vol. 25, no. 1, pp. 1-20, 2014.

[14] E. Purba, "Peranan Teknologi Informasi Dalam Mengefektifkan Keputusan Pemberian Dana Corporate Social Responsibilty ( CSR )," Media Inform. Budidarma, vol. 2, no. 3, pp. 69-75, 2018.

[15] S. Barus, V. M. Sitorus, D. Napitupulu, M. Mesran, and S. Supiyandi, "Sistem Pendukung Keputusan Pengangkatan Guru Tetap Menerapkan Metode Weight Aggregated Sum Product Assesment ( WASPAS )," MEDIA Inform. BUDIDARMA, vol. 2, no. 2, pp. 10-15, 2018.

[16] S. Sugiarti, D. K. Nahulae, T. E. Panggabean, and M. Sianturi, "Sistem Pendukung Keputusan Penentuan Kebijakan Strategi Promosi Kampus Dengan Metode Weighted Aggregated Sum Product Assesment ( WASPAS )," vol. 5, no. 2, pp. 103-108, 2018. 